\title{
Excretion of Vasopressin in the Hypoxic Lamb: Comparison between Fetus and Newborn
}

\author{
SALHA S. DANIEL, (2) RAYMOND I. STARK, M. KAZIM HUSAIN, ULANA M. SANOCKA, AND \\ L. STANLEY JAMES \\ Division of Perinatal Medicine, Departments of Anesthesiology and Pediatrics, College of Physicians and \\ Surgeons, Columbia University, New York, New York, USA
}

\begin{abstract}
Summary
The factors associated with increased renal excretion of vasopressin (VP) were examined in the hypoxic fetus and newborn. Studies were conducted on six chronically instrumented fetal (117-136 days gestation) and seven newborn lambs (2-6-dayold). Hypoxia was produced by administration of $10 \%$ oxygen to the ewe or neonate for $30 \mathrm{~min}$. This procedure caused a $\mathbf{5 0 \%}$ reduction in $\mathrm{PaO}_{2}$, no significant change in $\mathrm{pHa}$ in either fetus or neonate and a slight fall in $\mathrm{PaCO}_{2}$. Hypoxia caused an increase in VP concentrations in plasma from $1.3 \pm 0.53$ to $46.4 \pm 4.71$ $\mathrm{pg} / \mathrm{ml}$ in the fetus and from $5.9 \pm 2.80$ to $50.2 \pm 26.68 \mathrm{pg} / \mathrm{ml}$ in the neonate. After hypoxia there was a fall in urine output from $0.27 \pm 0.045$ to $0.17 \pm 0.046 \mathrm{ml} /(\mathrm{min} \cdot \mathrm{kg})$ in the fetus and from $0.15 \pm 0.033$ to $0.09 \pm 0.022 \mathrm{ml} /(\mathrm{min} \cdot \mathrm{kg})$ in the newborn. The corresponding values for urine osmolality were the following: 168 \pm 30.8 to $325 \pm 30.6 \mathrm{mOsm} / \mathrm{kg}$ in the fetus and $388 \pm 65.4$ to $523 \pm 51.8 \mathrm{mOsm} / \mathrm{kg}$ in the newborn. VP concentration in urine increased from $13 \pm 9.4$ to a maximum of $176 \pm 32.4 \mathrm{pg} / \mathrm{ml}$ after $30 \mathrm{~min}$ of recovery in the fetus and $39 \pm 4.6$ to $278 \pm 132.5$ $\mathrm{pg} / \mathrm{ml}$ after $1 \mathrm{~h}$ of recovery in the newborn. These levels remained high for at least $1 \mathrm{~h}$ after the end of hypoxia. There was a good linear correlation between plasma VP levels and the corresponding urine levels and excretion rates in both the fetus and newborn. No correlation was found between VP urinary excretion and either osmolar excretion or GFR. These results, therefore, indicate that urinary VP levels and excretion rates can be used as a reflection of levels in plasma after hypoxia.
\end{abstract}

\section{Abbreviations}

GFR, glomerular filtration rate

$\mathrm{Na}$, sodium concentrations

OSM, plasma osmolality

VP, vasopressin

Measurements of urinary excretion of VP have been used in some clinical situations in order to assess neurohypophisial function $(10,12,13)$. The use of urine for this purpose would offer the advantage of reducing the number and volume of blood samples as well as the need for a very sensitive assay because concentrations in the urine are usually higher than in the plasma. But, Robertson (14) reported that VP excretion varied more with solute excretion than plasma concentration and, in the newborn, Goddard et al. (7) found that urinary VP is correlated with glomerular filtration rate. The purpose of the present study is to examine the factors associated with increased renal excretion of VP in the hypoxic fetus and newborn.

\section{MATERIALS AND METHODS}

Fetal surgery. Instrumentation of six fetal lambs was performed after laparatomy and hysterotomy as described previ- ously (4) on mixed breed pregnant ewes at 110-118 days gestation. Polyethylene catheters were placed in the fetal carotid artery and jugular vein, into the fetal bladder via the urachus, and in the amniotic cavity. Through a separate incision, the maternal femoral artery and vein were also catheterized. Penicillin and chloromycetin were given intravenously to both the ewe and the fetus for the first 3 post-operative days and after each experiment. All catheters were cleaned and flushed daily and vascular catheters kept filled with $100 \mathrm{U} / \mathrm{ml}$ heparin.

Newborn surgery. Experiments were conducted on seven lambs, 2-7-day-old. Five of the instrumented fetuses were born spontaneously per vaginum and were used in the neonatal experiments. In two of these, catheters were placed in the femoral artery and vein because the neck catheters placed in utero had become dislodged during delivery; two non-instrumented twins were also catheterized at 1-2 days of age. All bladder catheters placed in utero were dislodged during delivery; thus, the bladder was catheterized in the seven neonates by suprapubic puncture after a small abdominal skin incision. Catheterization was performed under local anesthesia with $0.5 \%$ lidocaine and light sedation with $1 \mathrm{mg} / \mathrm{kg}$ phencyclidine intramuscularly. Antibiotics were administered on the day of surgery and after the experiment.

Experimental procedure, control period. Experiments were conducted at least 6 days after surgery on the fetus and after 1 day on the newborn. As described previously (4), the ewe was standing in a cart with free access to food and water and the neonate was lightly restrained, its body temperature maintained at $39^{\circ} \mathrm{C}$ and kept well hydrated with $0.2 \mathrm{ml} /(\mathrm{min} \cdot \mathrm{kg}) 5 \%$ glucose in $0.45 \%$ saline intravenous infusion throughout the experiment as has been described previously (5). Fetal, maternal, and newborn $\mathrm{pHa}, \mathrm{PaO}_{2}$ and $\mathrm{PaCO}_{2}$ were measured before any experiment and only animals with normal arterial acid base state and oxygenation were included in the study.

After a period of stabilization of $2 \mathrm{~h}$, the lamb's bladder was emptied; $10 \mu \mathrm{Ci} / \mathrm{kg}$ sodium iothalamate $\left[{ }^{125} \mathrm{I}\right]$ was injected intravenously into the lamb for measurement of GFR as described by Cohen and co-workers (3); urine collection for isotope determination was started 30 min after the injection. Samples from at least two 30-min collection periods were obtained from each animal. Arterial blood samples for biochemical determinations were taken from the ewe and the fetal or newborn lamb midway through the urine collection. During the period of study, the curve describing the $\log$ disappearance of $\left[{ }^{125} \mathrm{I}\right]$ in plasma remained linear. In the fetus, a slightly hypotonic saline solution (osmolality $200 \mathrm{mOsm} / \mathrm{kg}$ ) was infused into the amniotic cavity at a rate equal to urine output in order to avoid reduction of volume in this compartment.

Experimental period: hypoxia and recovery. Neonate and pregnant ewes were given $10 \%$ oxygen in nitrogen to breathe for a period of $30 \mathrm{~min}$. The mixture was administered at 2-3 and 46 liter/min into polyethylene bags fitted over their heads. Arterial pressure, corrected for intrauterine pressure and heart rate of the 
ewe, fetus, and neonate were recorded throuughout in order to monitor their cardiovascular condition. Fetal and neonatal responses were observed during and after $90 \mathrm{~min}$ of recovery from the hypoxic stress.

Sampling and measurements. Arterial blood samples were obtained from the fetus and newborn before, at the end of, and $30 \mathrm{~min}$ after the episode of hypoxia. Samples of $4.0 \mathrm{ml}$ each were withdrawn by chilled heparinized syringes and immediately divided into three portions: $1.7 \mathrm{ml}$ was transferred into chilled tubes containing $5 \mathrm{mg}$ EDTA to be used for analysis of VP; 1.7 $\mathrm{ml}$ was transferred into plain tubes for measurements of osmolality, electrolytes, and radioactivity; and the remainder was used immediately for measurement of acid base indices. Blood for VP and electrolytes was centrifuged at $4^{\circ} \mathrm{C}$ and the plasma kept frozen at $-20^{\circ} \mathrm{C}$ until analysis.

Separate samples of urine were collected in 30 -min portions for $1-2 \mathrm{~h}$ before, during $30 \mathrm{~min}$ of hypoxia, and for $9.0 \mathrm{~min}$ of recovery. The volume was recorded after each 30 -min interval. One portion of the urine was transferred to tubes containing EDTA for measurement of VP and the remainder was kept in plain tubes for measurements of electrolytes and radioisotope. Both portions were stored at $-20^{\circ} \mathrm{C}$ until analysis.

Biochemical analysis. Arterial blood pH and gas analyses were performed immediately using Radiometer microelectrodes and blood gas monitor (19). Osmolality, sodium, and potassium were determined using a freezing point depression and a flame photometry technique respectively $(4,18)$. [ $\left.{ }^{125} \mathrm{I}\right]$ was measured in both plasma and urine using a gamma counter. Plasma and urine VP was determined as described previously by radioimmunoassay using specific and sensitive antibody after extraction with petroleum ether and acetone mixtures $(5,8,13)$.

Calculations and statistical methods. GFR and clearances were calculated using the following formula:

$$
\mathrm{C}=\frac{(\mathrm{U}) \times(\mathrm{V})}{(\mathrm{P})}
$$

where C, clearance or GFR $[\mathrm{ml} /(\mathrm{min} \cdot \mathrm{kg})]$; (U), concentration in urine; (V) urine output $[\mathrm{ml} /(\mathrm{min} \cdot \mathrm{kg})]$; and $(\mathrm{P})$, concentration in plasma. Fractional Excretion $(\mathrm{FE})=(\mathrm{C} / \mathrm{GFR}) \times 100$.

Differences between the fetus and newborn were tested using the one way analysis of variance, whereas differences in means due to experimental procedure were analyzed using Student's $t$ test for paired and the Bonferroni method for multiple samples. Linear regression analyses were performed using the least square method for one independent variable. Differences were considered significant when $\mathrm{P}<0.05$.

\section{RESULTS}

Blood. Fetus. The change in fetal blood acid base and plasma composition with administration of $10 \%$ oxygen to the ewe are given in Table 1.

There was no significant change in $\mathrm{pHa}$ at the end of hypoxia; however, there was a small but significant fall $30 \mathrm{~min}$ later. $\mathrm{PaO}_{2}$ fell by $50 \%$ during $10 \% \mathrm{O}_{2}$ administration but returned to control levels during recovery. Similarly $\mathrm{PaCO}_{2}$ fell during hypoxia then returned to pre-experimental values after $30 \mathrm{~min}$ of recovery. $\mathrm{OSM}$ and $\mathrm{Na}$ concentrations rose significantly during hypoxia but returned to control levels during recovery. VP concentrations in plasma rose 20 -fold during hypoxia but were not significantly different from control $30 \mathrm{~min}$ later.

Newborn. Control $\mathrm{pHa}, \mathrm{PaO}_{2}$, and plasma VP values were significantly higher in the newborn than in the fetus $(P<0.05)$ whereas $\mathrm{PaCO}_{2}$, osmolality, and sodium were not significantly different. During hypoxia, $\mathrm{PaO}_{2}$ and $\mathrm{PaCO}_{2}$ fell whereas OSM and $\mathrm{Na}$ rose; $\mathrm{pHa}$ also rose but not significantly. As with the fetus, the changes in $\mathrm{PaO}_{2}, \mathrm{OSM}$, and $\mathrm{Na}$ were confined to the period of hypoxia. In contrast to the fetus, the fall in $\mathrm{PaCO}_{2}$ persisted to the recovery period. In general the rise in VP was proportionally less than in the fetus and the levels were still higher than control after $30 \mathrm{~min}$ of recovery.

Renal function. Fetus. Hypoxia was associated with a rise in urine osmolality and concentrations of sodium and VP; however, maximal concentrations occurred at various periods during the recovery and not during hypoxia (Table 2). Due to the fall in urine output the change in rate of excretion of osmolality and electrolytes, as well as osmolar clearance with hypoxia, was not significant (Fig. 1). Free water clearance fell significantly during hypoxia and early part of recovery. Clearance of VP fell from a control of 1.8 to $0.7 \mathrm{ml} /(\mathrm{min} \cdot \mathrm{kg}) 30-60 \mathrm{~min}$ after the end of hypoxia (Fig. 1). GFR was measured in three fetuses; there was a fall during hypoxia in all three fetuses and a return to control levels after $90 \mathrm{~min}$ of recovery. Fractional excretion of $\mathrm{Na}$ and OSM both rose with hypoxia reaching maximal levels during 30 min of recovery whereas fractional excretion of VP fell intially but rose 3-fold during recovery (Table 3 ).

Renal excretion of VP rose significantly from a control of 2 to a maximum of $29 \mathrm{pg} /(\mathrm{min} \cdot \mathrm{kg}$ ) at $45 \mathrm{~min}$ (Fig. 2). Osmolar excretion fell initially from 44 to 36 then rose later to a maximum of $57 \mu \mathrm{Osm} /(\mathrm{min} \cdot \mathrm{kg})$ at $75 \mathrm{~min}$. Linear regression analyses showed that there was a weak but significant correlation between plasma VP and urine osmolality $(r=0.665, P=0.005)$ and between urine osmolality and VP concentrations $(r=0.662, P$ $=0.006)$. A strong and significant correlation was found between

Table 1. Blood composition (mean $\pm S$.E.) before $(C)$, during 30 min of hypoxia $(H)$ and after 30 min of recovery from hypoxia $(R)$. Fetal gestational age was $124.3 \pm 3.06$ days and neonatal age was $2.7 \pm 0.52$ days

\begin{tabular}{|c|c|c|c|}
\hline & $\mathrm{C}$ & $\mathbf{H}$ & $\mathbf{R}$ \\
\hline \multicolumn{4}{|l|}{ Fetus } \\
\hline $\mathrm{pH}_{\mathrm{a}}$ & $7.375 \pm 0.006$ & $7.385 \pm 0.030$ & $7.345^{1} \pm 0.018$ \\
\hline $\mathrm{PaCO}_{2}(\mathrm{mmHg})$ & $42.5 \pm 1.15$ & $38.8^{1} \pm 0.61$ & $41.7 \pm 1.15$ \\
\hline $\mathrm{PaO}_{2}(\mathrm{mmHg})$ & $20.2 \pm 1.11$ & $10.7^{1} \pm 0.81$ & $20.0 \pm 0.93$ \\
\hline Total solutes $(\mathrm{mOsm} / \mathrm{kg})$ & $291.5 \pm 1.55$ & $294.5^{1} \pm 0.82$ & $288.5 \pm 1.71$ \\
\hline $\mathrm{Na}(\mathrm{mEq} /$ liter $)$ & $142.3 \pm 0.92$ & $146.8^{1} \pm 0.76$ & $143.0 \pm 1.21$ \\
\hline Vasopressin $(\mathrm{pg} / \mathrm{ml})$ & $1.33 \pm 0.53$ & $46.4^{1} \pm 4.71$ & $2.91 \pm 0.60$ \\
\hline \multicolumn{4}{|l|}{ Newborn } \\
\hline $\mathrm{pH}_{\mathrm{a}}$ & $7.401 \pm 0.016^{2}$ & $7.429 \pm 0.017^{2}$ & $7.403 \pm 0.016^{2}$ \\
\hline $\mathrm{PaCO}_{2}(\mathrm{mmHg})$ & $40.4 \pm 0.90$ & $34.4^{1} \pm 0.57^{2}$ & $36.1^{1} \pm 1.14^{2}$ \\
\hline $\mathrm{PaO}_{2}(\mathrm{mmHg})$ & $64.6 \pm 5.21^{2}$ & $22.9^{1} \pm 2.08^{2}$ & $70.6 \pm 2.18^{2}$ \\
\hline Total solutes $(\mathrm{mOsm} / \mathrm{kg})$ & $297.6 \pm 4.59$ & $306.4^{1} \pm 2.82^{2}$ & $295.0 \pm 2.78^{2}$ \\
\hline $\mathrm{Na}(\mathrm{mEq} / \mathrm{liter})$ & $142.9 \pm 0.63$ & $145.0^{1} \pm 0.41$ & $144.7 \pm 1.41$ \\
\hline Vasopressin $(\mathrm{pg} / \mathrm{ml})$ & $5.94 \pm 2.80^{2}$ & $50.18^{1} \pm 26.68$ & $11.18^{1} \pm 2.16^{2}$ \\
\hline
\end{tabular}

\footnotetext{
${ }^{1}$ Significantly different from control value.

${ }^{2}$ Significantly different from corresponding fetal value.
} 
Table 2. Urine composition (mean \pm S.E.) before $(C)$ during 30 min of hypoxia $(H)$ and 90 min of recovery $(R)$

\begin{tabular}{|c|c|c|c|c|c|}
\hline \multirow{2}{*}{$\begin{array}{c}\text { Period } \\
(\min )\end{array}$} & \multirow{2}{*}{$\frac{C}{-60 \text { to } 0}$} & \multirow{2}{*}{$\frac{\mathrm{H}}{0-30}$} & \multicolumn{3}{|c|}{$\mathrm{R}$} \\
\hline & & & $30-60$ & $60-90$ & $90-120$ \\
\hline Fetus & & & & & \\
\hline $\begin{array}{l}\text { Total solutes } \\
(\mathrm{mOsm} / \mathrm{kg})\end{array}$ & $168.2 \pm 30.77$ & $199.3 \pm 18.57$ & $325.3^{\prime} \pm 30.63$ & $258.9^{1} \pm 27.65$ & $180.6 \pm 26.58$ \\
\hline $\begin{array}{l}\mathrm{Na} \\
(\mathrm{mEq} / \mathrm{liter})\end{array}$ & $39.0 \pm 11.06$ & $51.2^{1} \pm 3.30$ & $92.8^{\prime} \pm 15.89$ & $75.8^{\prime} \pm 8.95$ & $58.5^{1} \pm 5.81$ \\
\hline $\begin{array}{l}\mathrm{K} \\
(\mathrm{mEq} / \mathrm{liter})\end{array}$ & $8.8 \pm 1.90$ & $9.9 \pm 1.11$ & $25.2^{1} \pm 4.37$ & $12.1 \pm 2.31$ & $7.8 \pm 1.14$ \\
\hline $\begin{array}{l}\text { Vasopressin } \\
(\mathrm{pg} / \mathrm{ml})\end{array}$ & $13.0 \pm 9.41$ & $64.7 \pm 51.7$ & $175.8^{\prime} \pm 32.39$ & $69.2^{1} \pm 22.97$ & $27.7 \pm 9.19$ \\
\hline \multicolumn{6}{|l|}{ Newborn } \\
\hline $\begin{array}{l}\text { Total solutes } \\
\text { (mOsm } / \mathrm{kg})\end{array}$ & $387.7 \pm 65.41^{2}$ & $441.7 \pm 26.08^{2}$ & $522.6^{1} \pm 51.75^{2}$ & $519.7^{1} \pm 53.73^{2}$ & $435.3 \pm 29.88^{2}$ \\
\hline $\begin{array}{l}\mathrm{Na} \\
(\mathrm{mEql} / \mathrm{liter})\end{array}$ & $27.0 \pm 15.68$ & $25.0 \pm 8.16^{2}$ & $38.9 \pm 9.84^{2}$ & $34.1 \pm 6.68^{2}$ & $24.9 \pm 2.05^{2}$ \\
\hline $\begin{array}{l}\mathrm{K} \\
(\mathrm{mEq} / \mathrm{liter})\end{array}$ & $20.7 \pm 8.35^{2}$ & $29.3 \pm 5.04^{2}$ & $35.6^{1} \pm 5.28$ & $33.7 \pm 4.93^{2}$ & $26.0 \pm 2.38^{2}$ \\
\hline $\begin{array}{l}\text { Vasopressin } \\
(\mathrm{pg} / \mathrm{ml})\end{array}$ & $38.9 \pm 4.64^{2}$ & $183.3 \pm 119.19$ & $278.0^{1} \pm 132.5$ & $215.1^{1} \pm 116.98$ & $150.3 \pm 118.61$ \\
\hline
\end{tabular}

' Significantly different from control value.

${ }^{2}$ Significantly different from the corresponding fetal value.

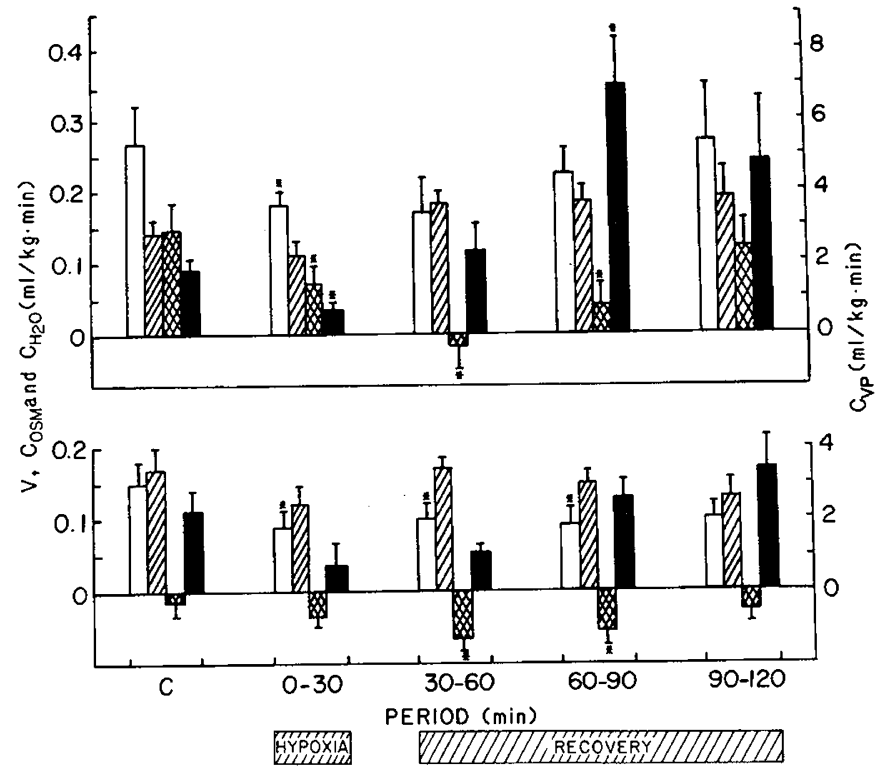

Fig. 1. Urine output $(\mathrm{V}, \square)$, Osmolar clearance ( $\left.\mathrm{C}_{\mathrm{OSM}}, \mathbb{C}^{2}\right)$, Free water clearance $\left(\mathrm{C}_{\mathrm{H} 2 \mathrm{O}}\right.$, 圈) and vasopressin clearance $\left(\mathrm{C}_{\mathrm{VP}}, \boldsymbol{\square}\right)$ in six fetuses (upper) and seven neonates (lower) before $(C)$ during 30 min of hypoxia $(H)$ and 90 min of recovery $(R)$ (mean \pm S.E.).

VP concentration in plasma and the corresponding urine concentration of the hormone ( $r=0.808, P<0.001)$ (Fig. 3).

Neonate. During the control period, urine osmolality and VP concentration were higher in the neonate than in the fetus, and $\mathrm{Na}$ concentration was slightly but not significantly lower (Table 2 ). As in the fetus, hypoxia caused an increase in concentrations of total solutes and VP but the increase, although significant, was relatively smaller than in the fetus. Although Na concentration rose during the initial period of recovery from hypoxia, this rise was not significant. In contrast, potassium concentrations, which rose in parallel to $\mathrm{Na}$ in the fetus, showed a significant rise in the neonate (Table 2).

During control period urine output was lower in the neonate than in the fetus. Hypoxia caused a fall in urine output; however, unlike the fetus, this fall persisted during the recovery period
(Fig. 1). Neither osmolar nor electrolyte excretion changed significantly with hypoxia. Similarly hypoxia caused no change in osmolar or VP clearances; however, the fall in free water clearance was statistically significant.

As in the fetus, VP excretion rose significantly with hypoxia, from a control of 6 to a maximum of $45 \mathrm{pg} /(\mathrm{min} \cdot \mathrm{kg})$ and excretion rate was still elevated at $105 \mathrm{~min}$ (Fig. 2). Osmolar excretion fell initially from a cotnrol of 25 to 18 then rose to a maximum of $33 \mu \mathrm{Osm} /(\mathrm{min} \cdot \mathrm{kg})$ at $45 \mathrm{~min}$.

Hypoxia caused no significant change in GFR or fractional osmolar excretion. There was a slight but significant increase in fractional excretion of Na. Fractional excretion of VP fell significantly during hypoxia and the initial phase of recovery, then rose after $1 \mathrm{~h}$ of recovery; this rise was relatively smaller than in the fetus (Table 3 ).

As in the fetus, no correlation between VP excretion and either GFR or osmolar excretion was found by linear regression analyses. Similarly, there was no correlation between plasma osmolality and either plasma VP concentration, both in absolute and logarithmic values, or urine osmolality. In contrast to the fetus, there was also no correlation between plasma VP and urine osmolality, or between urine osmolality and the corresponding VP concentration. Again, a good positive correlation was found between plasma and urine VP concentrations $(r=0.726, P<$ 0.001) (Fig. 3).

\section{DISCUSSION}

Moderate acute hypoxia produced by inhalation of low oxygen mixtures caused an increase in urinary concentration and excretion of VP both in the fetus and newborn lamb. Urine VP concentration was proportional to plasma concentration and can thus be used as a reflection of VP secretion under hypoxic conditions.

Despite the mild hypocarbia, pHa was not significantly changed during low oxygen breathing because of a small metabolic acidosis that developed during and after the hypoxic episode $(15,20)$. In addition to changes in $\mathrm{PaCO}_{2}$, hypoxia also caused a rise in plasma osmolality and $\mathrm{Na}$ concentration as described by others in both the adult and fetal animals $(11,15)$. These changes were confined to the period of hypoxia. Despite the wide scatter, particularly in the newborn, the rise in VP concentrations in 
Table 3. Glomerular filtration rate $(G F R)$ and fractional excretion of sodium ( $\left.F E_{N a}\right)$, total solutes $\left(F E_{O S M}\right)$, and vasopressin ( $\left.F E_{V P}\right)$ in three fetuses (mean and range) and on seven neonates (mean $\pm S . E$.) before $(C)$, during 30 min of hypoxia $(H)$, and 90 min of recovery $(R)$

\begin{tabular}{|c|c|c|c|c|}
\hline & \multirow{2}{*}{$\begin{array}{c}\mathrm{C} \\
-60 \text { to } 0 \\
(\mathrm{~min})\end{array}$} & \multirow{2}{*}{$\begin{array}{c}\mathrm{H} \\
0-30 \\
(\mathrm{~min}) \\
\end{array}$} & \multicolumn{2}{|c|}{$\mathbf{R}$} \\
\hline & & & $\begin{array}{l}30-60 \\
(\mathrm{~min})\end{array}$ & $\begin{array}{l}60-90 \\
(\mathrm{~min})\end{array}$ \\
\hline \multicolumn{5}{|l|}{ Fetus } \\
\hline GFR & 2.2 & 1.3 & 1.8 & 1.7 \\
\hline$[\mathrm{ml} /(\mathrm{kg} \cdot \mathrm{min})]$ & $(1.7-2.5)$ & $(1.0-1.9)$ & $(1.3-2.4)$ & $(1.2-2.5)$ \\
\hline $\mathrm{FE}_{\mathrm{Na}}(\%)$ & $\begin{array}{c}2.7 \\
(1.8-3.5)\end{array}$ & & $\begin{array}{c}.3 \\
(2.0-7.6)\end{array}$ & $\begin{array}{c}6.1 \\
(4.0-8.0)\end{array}$ \\
\hline & & $\begin{array}{c}6.4 \\
(2.7-10.1)\end{array}$ & & \\
\hline $\mathrm{FE}_{\mathrm{OSM}}(\%)$ & $\begin{array}{c}6.3 \\
(5.2-7.6)\end{array}$ & $\begin{array}{c}8.0 \\
(6.8-9.7)\end{array}$ & $\begin{array}{c}9.6 \\
(8.4-11.3)\end{array}$ & $\begin{array}{c}9.8 \\
(5.9-15.5)\end{array}$ \\
\hline $\mathrm{FE}_{\mathrm{VP}}(\%)$ & $\begin{array}{c}111.1 \\
(77.2-146.5)\end{array}$ & $\begin{array}{c}85.4 \\
(59.0-142.9)\end{array}$ & $\begin{array}{c}158.7 \\
(92.4-285.0)\end{array}$ & $\begin{array}{c}314.6 \\
(216.0-485.0)\end{array}$ \\
\hline \multicolumn{5}{|l|}{ Newborn } \\
\hline $\begin{array}{l}\text { GFR } \\
{[\mathrm{ml} /(\mathrm{kg} \cdot \mathrm{min})]}\end{array}$ & $3.1 \pm 0.45$ & $2.7 \pm 0.25$ & $2.6 \pm 0.37$ & $2.7 \pm 0.41$ \\
\hline $\mathrm{FE}_{\mathrm{Na}}(\%)$ & $1.7 \pm 0.38$ & $1.4 \pm 0.15$ & $3.0^{1} \pm 0.52$ & $1.5 \pm 0.17$ \\
\hline FE osm (\%) & $6.9 \pm 1.14$ & $5.1 \pm 0.56$ & $8.3 \pm 1.42$ & $6.3 \pm 0.73$ \\
\hline $\mathrm{FE}_{\mathrm{VP}}(\%)$ & $67.5 \pm 10.15$ & $19.2^{1} \pm 6.69$ & $40.5^{1} \pm 14.25$ & $84.3 \pm 19.36$ \\
\hline
\end{tabular}

'Significantly different from control value.

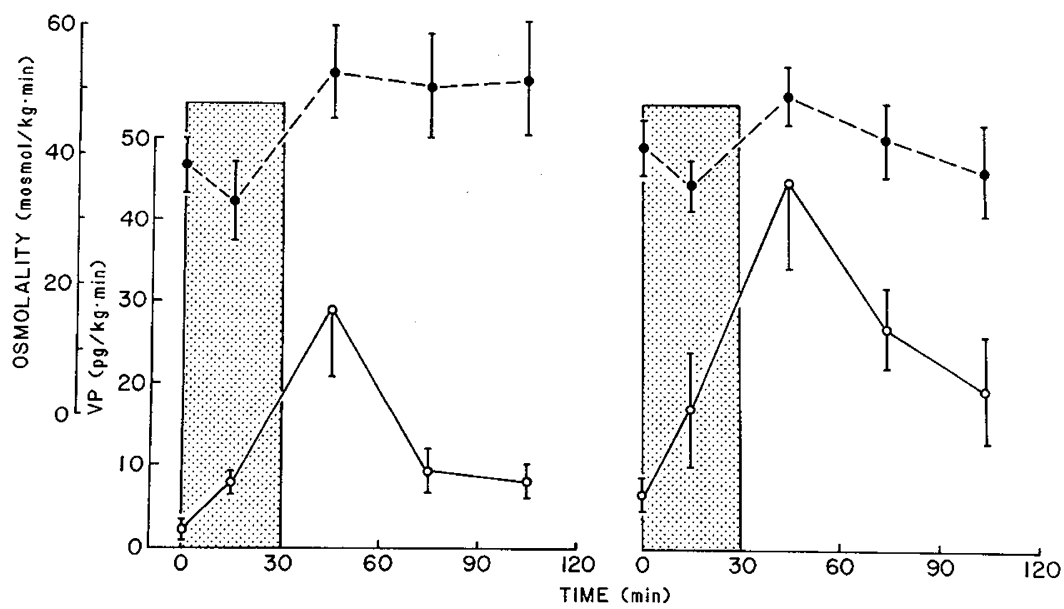

Fig. 2. Excretion of total solutes (OSM, - - - $)$ ) and vasopressin $\left(\mathrm{VP}, \mathrm{O}_{-}-\mathrm{O}\right)$ in six fetuses $($ left $)$ and seven neonates (right) before, during 30 min of hypoxia at time zero $(H)$ and 90 min of recovery $(R)$. Plotted at mid-points of urine collection (mean \pm S.E.). Shaded area represents period of hypoxia.

plasma was much higher than predicted on the basis of plasma osmolality alone (5).

In agreement with Robillard et al. (15), hypoxia in the fetus caused a fall in urine output and elevation in urine solute concentration that led to a decrease in free water clearance from positive to slightly negative values. Our experiments show that a similar change in urine output and concentration also occurs in the newborn. This is contrary to the findings of Rowe and Strauss (16), using piglets, and could be related to the degree of hypoxia. The fall in urine output was accompanied in both fetus and newborn by a small, although not significant, fall in GFR. The antidiuresis could be in part due to the effect of VP. The increase in urine concentration, particularly in the fetus, appears to be also due to a decrease in $\mathrm{Na}$ and solute tubular reabsorption.

Antidiuresis persisted throughout $90 \mathrm{~min}$ of recovery from hypoxia in the newborn. This is likely in response to VP concentration in plasma, which also remained elevated. In the fetus, hypoxia appears to cause a transient antidiuresis but persistent decrease in tubular electrolyte reabsorption whereas in the new- born the effect of hypoxia on renal function is a more transient decrease in electrolyte reabsorption but a more persistent antidiuresis. This difference may be due to the fact that a $50 \%$ reduction in $\mathrm{PaO}_{2}$ does not represent the same degree of hypoxia in the fetus as in the newborn.

During control periods VP excretion in our study was found to be 2.3 in the fetus and $6.5 \mathrm{pg} /(\mathrm{min} \cdot \mathrm{kg})$ in the newborn. These values correspond to 3.1 and $9.4 \mathrm{ng} \cdot \mathrm{kg} \cdot 24 \mathrm{~h}^{-1}$ in the fetus and neonate, respectively. The rate of VP excretion in the fetus and newborn lamb is, thus, much higher on a body weight basis than the amount excreted by an adult human on a normal $\mathrm{Na}$ intake, and is in the range of values reported by Goddard et al. (7) in the human neonates $(6,10)$.

The source of VP in the urine in the adult animal has been shown to be mainly glomerular filtration (1); thus, excretion of VP should vary with both GFR and plasma concentration (VP load), VP clearance should thus be similar to GFR. Our results from the fetus and newborn lamb show that during control period, $C_{V P}$ is of the same magnitude as GFR and changes in the 


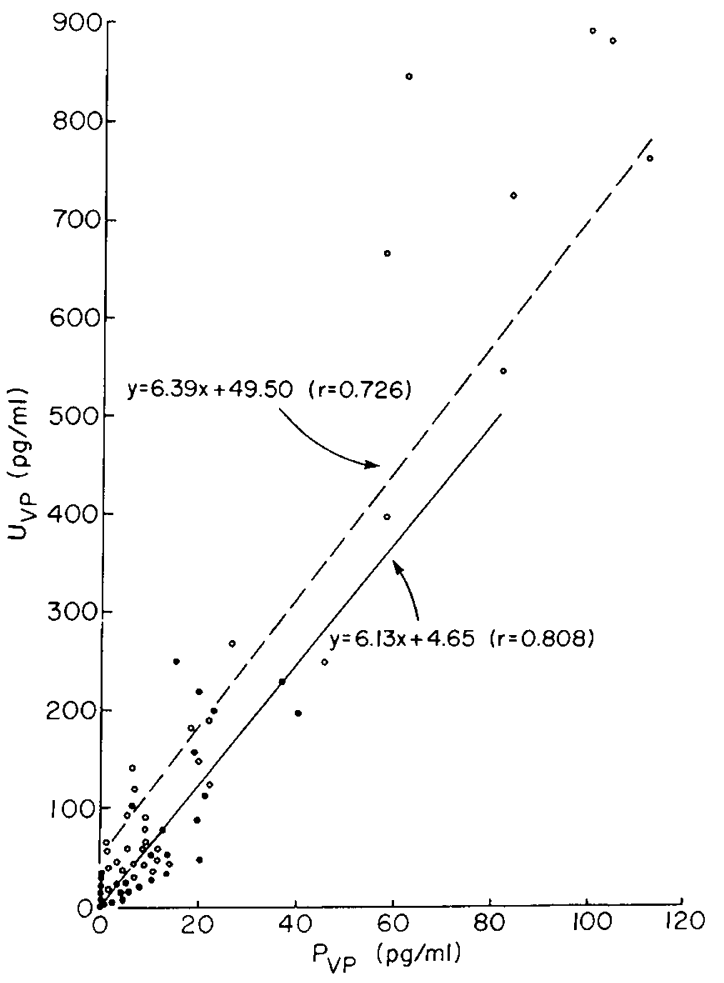

Fig. 3. Relationship between vasopressin concentration in plasma and in urine before, during, and after hypoxia in the fetus (-) and newborn (O- -).

same direction during hypoxia and recovery. Despite a good correlation between plasma and urine VP concentration, the highest rates of urinary excretion and concentration occurred during the recovery period from hypoxia when plasma levels were already decreasing. This is likely due to the rapidly changing plasma VP concentration and to the lapse of time between filtration and appearance of urine in the bladder. But the possibility of tubular VP secretion cannot at present be excluded.

Contrary to the results reported by Robertson (14) in the human adults undergoing water or saline loading, our results on VP excretion in the fetal and newborn during hypoxia did not always follow the changes in osmolar excretion. In our experiments, the changes in VP concentrations in plasma and urine were much higher than those produced by Robertson.

The calculated values of renal clearance before and after hypoxia indicate that the relative contribution of the kidney to the clearance of VP in the fetus and newborn is relatively small (14). The rate of decline of plasma VP concentration during the recovery period, i.e., overall clearance, is slower in newborn lamb than in the fetus. This finding is in agreement with the conclusion made by Jones and Rurak (9) that in the fetus, the placenta participates in the metabolism of VP.

In conclusion, these experiments indicate that, during and after periods of hypoxia in the newborn lamb, urinary VP concentration and excretion are related to plasma concentration. They can therefore be used as a reflection for the occurrence of moderate hypoxic episodes. Although plasma VP concentrations correlate inversely with fetal oxygenation (17), our results suggest that the concentration of VP in amniotic fluid may prove to be useful index for the occurrence of intrauterine hypoxia. Whether the same conclusion holds in the presence of asphyxia or severe hypoxia when acidosis and impairment of both circulation and renal function also occur is not known.

\section{REFERENCES AND NOTES}

1. Bauman, G. and Dingman, J. F.: Distribution, blood transport and degradation of antidiuretic hormone in man. J. Clin. Invest., 57: 1109 (1976).

2. Bowman, R. L., Trantham, H. V., and Caulfield, P. A.: An instrument and method for rapid dependable determination of freezing point depression. J. Lab. Clin. Med., 43: 310 (1954).

3. Cohen, M. L., Smith, F. G., Jr., Mindell, R. S., and Vernier, R. L.: A simple reliable method of measuring glomerular filtration rate using single low dose Iothalamate 1-131. Pediatrics, 43: 407 (1969)

4. Daniel, S. S., Yeh, M.-N., Bowe, E. T., Fukunaga, A., and James, L. S.: Renal response of the lamb fetus to partial occlusion of the umbilical cord. J Pediatr. 87: 788 (1975).

5. Daniel, S. S., Stark, R. I., Husain, M. K., Baxi, L. A., and James, L. S.: Role of vasopressin in fetal homeostasis. Am. J. Physiol., 242: F740 (1982).

6. Geelen, G., Allevard, A. M., Jarasaillan, E., Zebida, A., Augayard, G., Baratin, D., and Gharib, C.: Elimination urinaire d'ocytocine et de vasopressine mesurees par radioimmunodosage au cours des differentes phases du cycle menstruel chez la femme. C. R. Soc. Biol., 173: 1036 (1979).

7. Goddard, C., Geering, J.-M., Geering, K., and Vallotton, M. B.: Plasma renin activity related to sodium balance, renal function and urinary vasopressin. Pediatr. Res., 13: 742 (1979)

8. Husain, M. K., Fernando, N., Shapiro, M., Kagen, A., and Glick, S. M.: Radioimmunoassay of arginine vasopressin in human plasma. J. Clin. Endocrinol. Metab., 37: 616 (1973).

9. Jones, C. T. and Rurak, D. W.: The distribution and clearance of hormones and metabolites in the circulation of the foetal sheep. Q. J. Exp. Physiol. 61: 287 (1976).

10. Merkelbach, U., Czernichow, P., Gaillard, R. C., and Vallotton, M. B.: Radioimmunoassay of 8-arginine-vasopressin. II. Application to determination of antidiuretic hormone in urine. Acta Endocrinol., 80: 453 (1975).

11. Meschia, G., Hellegers, A., Baron, D. H., and Battaglia, F. C.: The effects of acute hypoxia on the osmotic pressure of the plasma. Q. J. Exp. Physiol., 42: 197 (1957).

12. Miller, M. and Moses, A. M.: Urinary antidiuretic hormone in polyuric disorders and in inappropriate ADH syndrome. Ann. Intern. Med., 77: 715 (1972).

13. Omaya, S. N., Kagan, A. and Glick, S. M.: Radioimmunoassay of vasopressin: application to unextracted human urine. J. Clin. Endocrinol. Metab., 33: 739 (1971).

14. Robertson, G. L.: The regulations of vasopressin function in health and disease. Recent. Progr. in Hormone Res., 33: 333 (1977).

15. Robillard, J. E., Weitzman, R. E., Burmeister, L., and Smith, F. G. Jr.: Developmental aspects of the renal response to hypoxemia in the lamb. Circ. Res., 48: 128 (1981).

16. Rowe, M. I., and Strauss, J.: The renal response of the newborn to hypoxia. Pediatr. Res., 7: 411 (1973).

17. Rurak, D. W.: Plasma vasopressin levels during hypoxaemia and the cardiovascular effects of exogenous vasopressin in foetal and adult sheep. J. Physiol. (Lond.), 277: 391 (1978).

18. Sanz, M. C.: Ultramicro methods and standardization of equipment. Clin. Chem., 3: 406 (1957).

19. Siggaard-Anderson, O.: Blood acid-base alignment nomogram. Scand. J. Clin. Lab. Invest., 15: 211 (1963).

20. Wardlaw, S. L., Stark, R. I., Daniel, S. S., and Frantz, A. G.: Effects of hypoxia on B-endorphin and B-lipotropin release in fetal, newborn and maternal sheep. Endocrinology, 108: 1710 (1981).

21. Requests for reprints should be addressed to: Dr. S. S. Daniel, Columbia University, College of Physicians and Surgeons, Department of Anesthesiology, 630 West 168th Street, New York, NY 10032.

22. This research was supported in part by U.S. Public Grant \#R01 HD 12737.

23. Received for publication December 22, 1981.

24. Accepted for publication March 18, 1983. 